\title{
Effect of Mirror Visual Feedback on Upper Extremity Function and Wrist Proprioception in Cerebral Palsy Children with Hemiparesis
}

\author{
Hatem Abd Al-Mohsen Emara ${ }^{1,2}$, Tamer Emam El Negamy ${ }^{3}$ \\ ${ }^{1}$ Department of Physical Therapy for Growth and Development Disorders in Children and Its Surgery, Cairo University, Ghisa, Egypt \\ ${ }^{2}$ College of Medical Rehabilitation Sciences, Taibah University, Medina, Saudi Arabia \\ ${ }^{3}$ Department of Physical Therapy for Pediatrics, Faculty of Physical Therapy, October 6 University, 6th October City, Egypt
}

\section{Email address:}

drhamid.1980@gmail.com (H. A. Al-Mohsen E.)

\section{To cite this article:}

Hatem Abd Al-Mohsen Emara, Tamer Emam El Negamy. Effect of Mirror Visual Feedback on Upper Extremity Function and Wrist Proprioception in Cerebral Palsy Children with Hemiparesis. International Journal of Neurologic Physical Therapy.

Vol. 3, No. 4, 2017, pp. 28-34. doi: 10.11648/j.ijnpt.20170304.12

Received: June 2, 2017; Accepted: June 20, 2017; Published: October 10, 2017

\begin{abstract}
The function of the affected side in the hemiplegic cerebral palsy is influenced by muscle tone abnormality, change of proprioception, diminished power, and decreased the speed of movement, weak grasp, and release functions. Mirror therapy (MT) is a therapeutic technique that uses the interaction of visuomotor-proprioception inputs to improve movement performance of the affected limb. This study was done to investigate the effects of mirror visual feedback exercises on upper extremity function and on the alternation of wrist proprioception in children with hemiparesis. Thirty-two children with spastic hemiparesis from both sexes ranging in age from five to seven years represented the sample of the study. They were assigned randomly into two groups of equal number (control and study). Every child in both groups was evaluated at baseline and after 3 months of intervention using The Quality of Upper Extremity Skills Test to evaluate movement patterns and hand function. Also, electro-goniometer was used to assess repositioning error through Active Reproduction of Active Positioning test (ARAP). The control group received a selected exercise program, while the study group received mirror visual feedback (MVF) exercises program training in addition to the same exercise program given to control group. Comparison of the pretreatment results of the two groups revealed no significant differences in all variables, while significant improvements were observed in all the measuring variables of the two groups when comparing their pre and post-treatment mean values. Significant differences were also observed when comparing the post-treatment results of the two groups in favor of the study group. MVF exercises could be used together with a therapeutic exercise program for the enhancement of hand function and wrist proprioception in children with hemiparesis.
\end{abstract}

Keywords: Hemiplegic Cerebral Palsy, Mirror Therapy, Wrist Proprioception, Upper Extremity Function

\section{Introduction}

Cerebral palsy $(\mathrm{CP})$ can be defined as a range of disorders of the motor and postural development that cause functional limitations caused by non-progressive lesions arising in the developing fetal or infant brain $[1,2]$.

Hemiplegia is one of the most common types of cerebral palsy and constitutes a major form among spastic types. It accounts about one-third of all cerebral palsy children as a result of unilateral brain lesion [3]. Spastic hemiplegia is characterized by spasticity in the arm and leg on one side of the body and most of them walk independently but there is wide variation in the function of the affected arm and hand [4].

Upper limb function problems in children with $\mathrm{CP}$ are associated with deficits in motor control, weakness, dystonia, sensation and the persistence of the grasp reflex [5]. This can result in abnormal joint postures, reduced muscle extensibility and disuse which further limits upper limb function that is associated with difficulties with reaching, pointing, grasping, releasing and manipulating objects [6]. While the impact of upper limb dysfunction varies from child to child, it has been well documented that this has a 
pronounced effect on their self-care activities [7], leading to an inability to accomplish activities of daily living and becoming independent [8]. If the child cannot interact with the environment or is dependent on someone else for that interaction to occur, occupational deprivation becomes apparent, resulting in poor quality of life for the child and their caregivers [9].

The usage of mirror visual feedback (MVF) is a simple non-invasive neurorehabilitation method for the management of two conditions that have long been considered as everlasting and mostly irredeemable; chronic pain that has central origin (for example phantom pain) and hemiparesis resulting from a stroke. Later studies were done based on these results and using visual feedback created by virtual reality, mirrors or, to some extent, even through intense visualization (which excite the same neural networks as those activated by MVF) [10].

The idea of mirror therapy is to use the mirror to produce the illusion for the patient that both limbs are intact. The effects of mirror therapy on upper extremity motor recovery and hand function of patients with subacute stroke were evaluated. The study found more improvement in hand function in the study group when compared with a control group after 4 weeks of treatment and at the 6-month followup [11].

Briefly, several studies have demonstrated that MVF might be an effective way to enhance UE recovery beyond more traditional rehabilitation ways that are founded on passive or active movement. Though, it remains undefined which functions can be improved. Therefore, our randomized controlled trial was performed to assess the effect of MVF on upper limb function and wrist proprioception in CP children with hemiparesis.

\section{Methods}

\subsection{Study Design}

This study was a randomized controlled trial.

\subsection{Subjects}

Thirty-two children diagnosed with hemiparesis (14 girls and 18 boys; 17 right sided and 15 left sided), their age ranged from 5 to 7 years $(\bar{x}=5.92 \pm 0.5$ years $)$ represented the sample of this study (figure 1). They were selected from outpatient clinic, Faculty of Physical Therapy, Cairo University. Inclusion criteria were: spasticity from 1 to $1^{+}$ according to the Modified Ashworth Scale [12]. They were able to understand instructions or commands in both testing and training sessions, and they had some voluntary control over the antispastic muscle groups. Exclusion criteria were: vision or hearing loss or structural deformities of the affected upper limb, however, participants had various degrees of tightness. Participants were randomly assigned to two equal groups by asking each subject to pick up an index card out of a box containing 32 cards (16 cards for each group) to determine which group he/she would be in.
Control group received a selected therapeutic exercise program, while study group received MVF as well as the same exercise program given to the control group. Each child received instructions about testing purpose and methods with enough training for all measurement procedures to be sure that he or she has become familiar with the test.

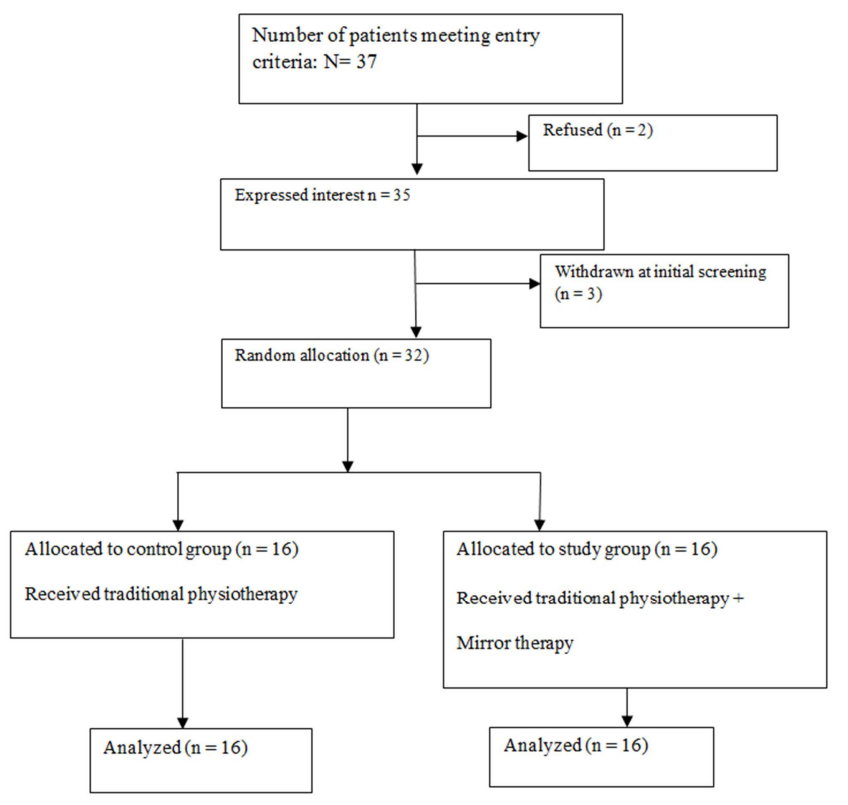

Figure 1. Flow diagram of intervention.

\subsection{Materials}

\subsubsection{For Evaluation}

The Quality of Upper Extremity Skills Test ( QUEST)

The QUEST contains 34 items. It evaluates forms of movement and hand function in CP children. There are four domains: grasp, dissociated movement, weight bearing, and protective extension. The whole score of each domain is the sum of item scores that is converted into a standardized percentage and the overall score of the subject is the average of the five domain scores. Although the test was originally performed on children with $\mathrm{CP}$ aged 18 months to 8 years, several studies have been used it with older children [13, 14 , $15,16]$. High internal consistency, interrater and intra-rater reliability have been established for the QUEST. There is, however, little studies concerning its validity with both age groups and children aged more than 8 years [17].

Electrogoniometer

An electro-goniometer (Biometrics, Model SG150) was used to determine both the degree of the wrist joint extension and reposition error. Electrogoniometer provides a valid and reliable measurement of joint range of motion [18].

\subsubsection{For Treatment}

1- A table and a sturdy chair: the table was with $60 \mathrm{~cm}$ height and a sturdy chair without armrests with $40 \mathrm{~cm}$ seating surface height

2-The mirror: A vertical wooden stand mirror, $(35 \times 35 \mathrm{~cm}$ zero lag mirror) was used. The mirror was formed of two wooden boards hinged together, one board $(35 \times 35 \mathrm{~cm})$ on 
which the mirror was stuck on its outer surface, the other board $(35 \times 40 \mathrm{~cm})$ which stabilizes the mirror piece in a vertical position by a hook.

\subsection{Procedures for Evaluation}

Before signing a written consent form, the researcher informed all participants and their parents about study procedures and gave them demonstration before testing to be sure that all subjects understood the steps of the test. Every participant in the two groups was assessed before and after 3 months of treatment. The evaluation was conducted for each child of both groups using QUEST to evaluate UE functions and electro-goniometer to determine the repositioning error through Active Reproduction of Active Positioning (ARAP) Test.

\section{1-QUEST administration}

Four physical therapists with 8 years of clinical experience in treating children with $\mathrm{CP}$ and experience in using the QUEST performed the QUEST according to the manual instructions. To enhance data consistency, all physical therapists had attended QUEST training before data gathering.

Materials used during test administration were either the same as those identified in the test manual or when the test manual allowed, they were varied to facilitate movements through demonstration, verbal encouragement, toys and handling the child as necessary.

2-Active Reproduction of Active Positioning Test (ARAP): Before the testing procedure, electro-goniometer measurement of the wrist joint was performed by the same assessor to exclude limitations in range of motion of wrist joint. ARAP test was used in this study for testing the presence of proprioceptive deficits in extension; the tested children were in sitting position with back support in front of a table. The forearm of the affected upper extremity was introduced in pronation in the testing box, so the patient cannot see his hand. Velcro straps were fastened around the forearm proximal to the wrist joint for fixation with wrist free from the box. The electro-goniometer was fastened on the ulnar border of the hand on the tested limb just distal to the wrist joint.

The assessor asked the child to move the wrist joint of the tested extremity in 15 and 30 degrees of wrist extension as instructed by the electro-goniometer examiner's guide [19] and holds it for $10 \mathrm{sec}$, and then the assessor instructed him to reposition the wrist to the initial position. The child was asked to actively reposition his wrist to the target angle. This procedure was repeated three times. Thirty seconds rest period was taken after each trial. The absolute angular errors were calculated as the difference between each trial and the target angle, then mean angular error was calculated [20].

\subsection{Procedures for Treatment}

The control group received a particularly designed physical therapy program. Whereas the study group received MVF training as well as the exercise program given to control group. Treatment was carried out 3 times/week, onehour session for 12 weeks. Designed exercise program included the following:

-Neuro- Developmental treatment program, using distal and proximal key points of control for the upper extremities, lower extremities, and trunk.

- Stretching exercises for all the muscles liable to be tight, namely wrist flexors, pronators, elbow flexors, iliotibial band, hip flexors, knee flexors and tendo-Achilles.

- Approximation for the upper extremity, lower extremity, and trunk from different positions.

- Facilitation of righting, equilibrium and protective reactions from different positions.

- Short width pulse electrical stimulation for wrist and fingers extensors of the hemiparetic side.

-Proprioceptive neuromuscular facilitation techniques for the upper and lower limbs.

Study group:

All patients in this group underwent 12 weeks of physical therapy intervention (30 minutes a day, 3 times a week). During mirror therapy session, the subject is able to look at the reflection of the sound limb and focus on it, which becomes the virtual image of the paretic extremity. During the mirror practices, patients were seated on a chair close to the table. The affected hand was placed behind the mirror and the noninvolved hand in front of the mirror. The exercise consisted of: extension and flexion of the shoulder, elbow and wrist and supination -pronation of the forearm, fanning out the hand, finger and thumb abduction, making a fist and release, lateral prehension, pad to side, pad to pad grip, grasping objects, thumb opposition, single finger movement [11], transfer cubes from one place to another while seeing his or her reflection in the mirror, squeezing a sponge ball, and drawing a circle (figue 2). During the session, patients were requested to attempt to perform the same movements with the affected hand as much as they could while they were exercising the non-paretic hand.

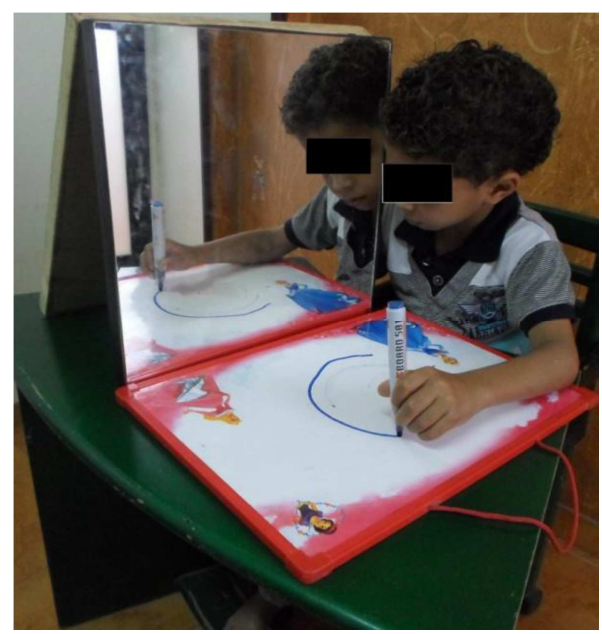

Figure 2. The child is drawing a circle with the unaffected hand.

\subsection{Data Analysis}

The obtained data was statistically analyzed using SPSS for windows, version16. The mean and standard deviation for each variable, for the control and study groups before and after 
three months following the application of the treatment was calculated. The normality of the data was examined using Kolmogorov-Smirnov statistic with Lilliefors significance level and Shapiro-Wilk test. The pre and post treatment results for each group were analyzed using paired t-test to determine the effect of each treatment. Independent t-test was done to compare the post treatment results between groups.

\section{Results}

There was no significant difference between the two groups regarding age $(\mathrm{P}>0.05)$, Also, no significant difference was found between both groups in gender, the degree of spasticity; the Chi-square value was 0.66 and 0.7 respectively ( $p>0.05)$. As revealed from the table (1, 2 and 3$)$ and demonstrated in figure (3 and 4), a non-significant difference was recorded in the mean values of all variables between control and study groups before treatment. Significant improvement was noted in the pre and post-treatment mean values of the QUEST of the control and study groups. Also, more improvement was also observed when comparing the post-treatment mean values of the QUEST of the two groups in favor of the study group $(\mathrm{P}<0.05)$.

Table (4 and 5) and figure (5) show and demonstrate a significant decrease in the mean values of angular error of $15^{\circ}$ and $30^{\circ}$ wrist extension for the control and study groups at the end of the treatment program as compared with the corresponding mean values before treatment. As shown in the table (6) and demonstrated in figure (5), significant improvement was also detected when comparing the posttreatment mean values of angular error of the two groups in favor of the study group $(\mathrm{P}<0.05)$.

Table 1. Pre and post-treatment mean values of the QUEST subtests for the control group.

\begin{tabular}{|c|c|c|c|c|}
\hline \multirow{2}{*}{ Item } & \multicolumn{2}{|c|}{ Control group $($ Mean \pm SD) } & \multirow{2}{*}{$t-$ test } & \multirow{2}{*}{$P$-value } \\
\hline & Pre & Post & & \\
\hline Dissociated movement & $52.990 \pm 2.552$ & $57.237 \pm 3.031$ & 4.382 & $0.001 *$ \\
\hline Grasp & $22.227 \pm 2.061$ & $24.970 \pm 1.131$ & 4.119 & $0.001 *$ \\
\hline Weight bearing & $25.918 \pm 1.147$ & $29.791 \pm 2.041$ & 6.812 & $0.000 *$ \\
\hline Protective extension & $20.254 \pm .731$ & $25.161 \pm 1.351$ & 12.093 & $0.000 *$ \\
\hline
\end{tabular}

SD: Standard deviation, $p$-value: Level of Significance, ${ }^{*}$ : Significant

Table 2. Pre and post-treatment mean values of the QUEST subtests for the study group.

\begin{tabular}{|c|c|c|c|c|}
\hline \multirow{2}{*}{ Item } & \multicolumn{2}{|c|}{ Study group (Mean \pm SD) } & \multirow[b]{2}{*}{$t-t e s t$} & \multirow{2}{*}{$P$-value } \\
\hline & Pre & Post & & \\
\hline Dissociated movement & $53.967 \pm 3.519$ & $63.548 \pm 4.862$ & 7.102 & $0.000^{*}$ \\
\hline Grasp & $23.155 \pm 2.034$ & $28.707 \pm 1.562$ & 10.962 & $0.000^{*}$ \\
\hline Weight bearing & $25.225 \pm 1.513$ & $32.267 \pm 2.746$ & 9.376 & $0.000^{*}$ \\
\hline Protective extension & $20.845 \pm .954$ & $27.458 \pm 1.524$ & 15.457 & $0.000^{*}$ \\
\hline
\end{tabular}

SD: Standard deviation, $p$-value: Level of Significance, *: Significant

Table 3. Post-treatment mean values of the QUEST subtests between both groups.

\begin{tabular}{|c|c|c|c|c|}
\hline & \multicolumn{4}{|c|}{ Mean \pm SD } \\
\hline & Dissociated movement & Grasp & Weight bearing & Protective extension \\
\hline Control group & $57.237 \pm 3.031$ & $24.970 \pm 1.131$ & $29.791 \pm 2.041$ & $25.161 \pm 1.351$ \\
\hline Study group & $63.548 \pm 4.862$ & $28.707 \pm 1.562$ & $32.267 \pm 2.746$ & $27.458 \pm 1.524$ \\
\hline t- test & 4.406 & 7.748 & 2.896 & 4.511 \\
\hline $\mathrm{p}$-value & $0.000 *$ & $0.000 *$ & $0.007^{*}$ & $0.000 *$ \\
\hline
\end{tabular}

SD: Standard deviation, $p$-value: Level of Significance, *: Significant

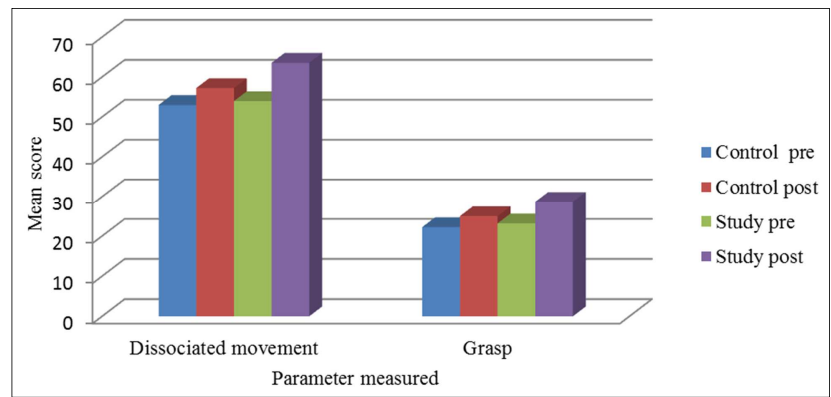

Figure 3. The pre and post-treatment mean values of QUEST (Dissociated movement and grasp) for both groups.

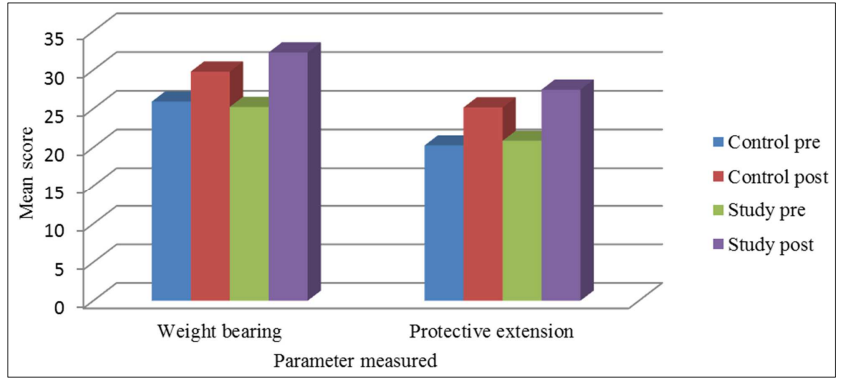

Figure 4. The pre and post-treatment mean values of QUEST (weight bearing and protective extension) for both groups. 
Table 4. Pre and post-treatment mean values of the angular error of $15^{\circ}$ and $30^{\circ}$ wrist extension for the control group.

\begin{tabular}{|c|c|c|c|c|}
\hline & \multicolumn{2}{|c|}{ Mean \pm SD } & \multirow{2}{*}{$t$ - test } & \multirow{2}{*}{$p$-value } \\
\hline & Pre & Post & & \\
\hline $15^{\circ}$ wrist extension & $9.378 \pm 0.516$ & $7.644 \pm 0.652$ & 9.408 & $0.000^{*}$ \\
\hline $30^{\circ}$ wrist extension & $13.163 \pm 1.23$ & $10.152 \pm 1.334$ & 7.353 & $0.000^{*}$ \\
\hline
\end{tabular}

SD: Standard deviation, $p$-value: Level of significance, ${ }^{*}$ : Significant

Table 5. Pre and post-treatment mean values of the angular error of $15^{\circ}$ and $30^{\circ}$ wrist extension for the study group.

\begin{tabular}{lllll}
\hline & \multicolumn{2}{c}{ Mean \pm SD } & $\boldsymbol{t}$ - test & $\boldsymbol{p}$-value \\
\cline { 2 - 5 } & Pre & Post & 15.232 & $0.000^{*}$ \\
\hline $15^{\circ}$ wrist extension & $9.855 \pm 0.599$ & $6.073 \pm 0.774$ & 8.277 & $0.000^{*}$ \\
$30^{\circ}$ wrist extension & $12.468 \pm 1.614$ & $8.975 \pm 1.592$ & \\
\hline
\end{tabular}

SD: Standard deviation, $p$-value: Level of Significance, ${ }^{*}$ : Significant

Table 6. Post-treatment mean values of the angular error of $15^{\circ}$ and $30^{\circ}$ wrist extension for the two groups

\begin{tabular}{lllll}
\hline & $\mathbf{1 5}^{\circ}$ wrist extension & & $\mathbf{3 0}^{\circ}$ wrist extension & \\
\cline { 2 - 5 } & Control group & Study group & Control group & Study group \\
\hline Mean \pm SD & $7.644 \pm 0.652$ & $6.0734 \pm 0.774$ & $10.152 \pm 1.343$ & $8.974 \pm 1.592$ \\
t-test & 6.205 & & 2.267 & \\
$p$-value & $0.000^{*}$ & & $0.031^{*}$ & \\
\hline
\end{tabular}

SD: Standard deviation, $p$-value: Level of significance, ${ }^{*}$ : Significant

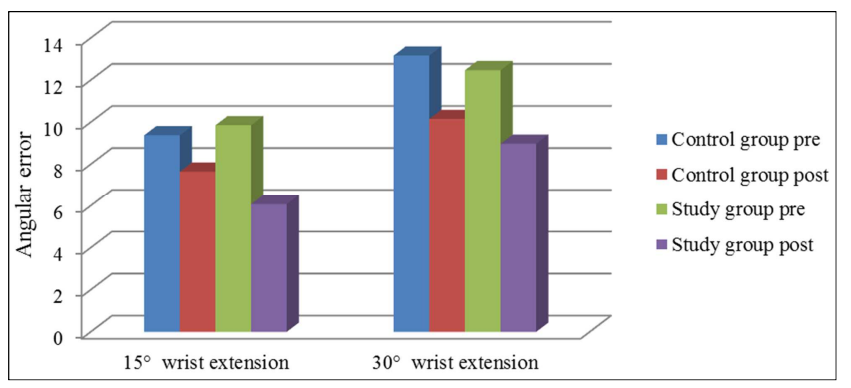

Figure 5. Demonstrating the pre and post-treatment mean values of angular error $15^{\circ}$ and $30^{\circ}$ wrist extension for both groups.

\section{Discussion}

The main purpose of this study was to determine the effect of mirror visual feedback on upper extremity function and wrist proprioception in cerebral palsy children with hemiparesis. We showed, in the current study, that use of MVF resulted in functional improvements in motor and sensory fields. The results are in agreement with previous neuro-physiological studies which demonstrated the importance of noticing mirrored movement in activation of the cortical function. Concerning motor function improvement, it has been shown that observation of movements of the mirrored limb improves excitability and function of the corticospinal tract, parallel to real movement performance [21, 22].

Often, effects of MVF could be explained by "mirror neurons" i.e., neurons located in the premotor area of both human beings and monkeys. These neurons are active during observation of purposeful movements [23, 24]. However, in a previous imaging research on visual feedback inversion, The lateralization of brain function was not recorded in the premotor area, but in posterior parietal and occipital regions [25]. Several researchers suppose that the precuneus region
(areaV6) plays an important role [26]. This area is one of the neural networks that help the cognitive representation of the self [27]. It was assumed that bilateral activation of the premotor areas, without lateralization, that occurs when the subject watches a healthy arm and hand moving in the neglected hemifield augments recovery from neglect than watching movements of a paretic side [28]. Consequently, the visual illusion that movements carried out by a person's selfare done normally explains to a great extent the beneficial effect of mirror therapy.

Mirror therapy in hemiplegia involves executing the movements of the non-paretic limb while viewing its mirror reflection superimposed over the hidden paretic limb [29]. This visual feedback can replace the lost proprioceptive feedback from the paretic limb[30]. Consequently, The increased excitability in the mirror neurons and the homologous motor pathways of the paretic limb, induced by the cross facilitatory drive from the intact hemisphere, enhances the readiness of these motor pathways and facilitates recovery of function [31].

The improvement of sensory deficits may be explained by that movement observation modifies not only the excitability of the motor cortex but also cortical somatosensory representations [32]. Enhancement of discrimination ability both in normal and in brain-damaged participants, accompanied by changes in excitation of the primary somatosensory cortex happens by viewing the stimulated body part [33]. Observing stimulation in a mirror can prompt transference of sensation to the other hand [34]. Our results support the hypothesis that patients with sensory deficits could benefit from MT. This improvement induced by crossmodal processes can be used therapeutically for longstanding improvement of somatosensory perception [10].

Additionally, the change in study group might be clarified by the effect of MT on the attentional process which is 
further illustrated by its advantageous impact on hemineglect. Ramachandran and coworkers[35] suggested reducing of hemineglect. They placed a mirror on the unaffected side of neglect patients to stimulate their alertness for the affected side. In our study, the mirror was located in the neglected hemifield. Clearly, one may accept that this change from hemineglect advances recovery in the motor and sensory field.

Mirror therapy is a type of motor imagery training during which representations of a given motor act are internally practiced in working memory without any obvious motor output [36]. The study group showed more significant improvement than the ordinary exercise therapy group. These outcomes are in line with the conclusions of two preceding studies. One made a comparison between motor imagery and real movement by means of cerebrum imaging and showed that both tasks brought about the arrangement of the same neural networks in the premotor cortex, parietal lobe and cerebellum [37], and the other demonstrated that motor imagery training increased dynamic balance ability by activating the neural system[38]. These results propose that the combination of motor imagery training and proprioception program resulted in activation of the cerebellum and cerebrum which in turn affected proprioception, and the visual and vestibular organs responsible for balance ability, especially, that the activation of the proprioception responsible for detecting the position and movements of joints affects the balance ability [39].

The obtained results of mirror therapy group are in accordence with Dhole et al. [26], who stated that mirror therapy is a hopeful technique to improve attentional and sensory deficits and to assist motor recovery in a hemiparetic extremity. The neurophysiological basis for mirror therapy is probably founded on the mirror mechanism which has been shown to improve upper limb function in post-stroke patients.

One of the limitations of this study was the small number of participants, making it hard to generalize our results. Based on the results of this study, it is recommended to evaluate the effect of mirror therapy program on upper limb control using electromyography. Evaluate the influence of mirror therapy with a larger sample to permit more statistical findings.

\section{Conclusion}

The results of this study suggested that mirror therapy could be used in addition to conventional physical therapy, as it is relatively effective, easy to conduct and easy to provide. Mirror therapy combined with the traditional physical therapy may represent a valid approach to enhance the motor recovery of upper limbs and improving functional ability of hemiparetic children. This helped the hemiparetic CP children to use their affected hand and increased their opportunity to receive sensory information from the environment and improved their performance in their daily living activities.

\section{References}

[1] Pfeifer LI, Silva DB, Funayama CA, Santos JL. Classification of cerebral palsy: association between gender, age, motor type, topography and Gross Motor Function. Arquivos de neuro-psychiatria. 2009;67 (4):1057-61.

[2] Molina-Rueda F, Águila-Maturana AM, Molina-Rueda MI, and Miangolarra-Page JC. Pasarelarodante con o sin Sistema de suspensióndel peso corporal enniños con parálisis cerebral infantile: revisiónsistemática y metaanálisis. Rev Neurol. 2010; 51:135-45.

[3] Bax M, Brown JK. The spectrum of disorders known as cerebral palsy. In ScruttonD, Mayston M. Management of the motor disorders of children with cerebral palsy, 2nd ed. London: Mac Keith Press. 2004, p: 9-21.

[4] Pountney T, Green E. The cerebral palsies and motor learning disorders. In. Stokes $M$ editor, Physical Management in Neurological Rehabilitation, Elsevier, Elsevier Mosby. 2004, p: 115.

[5] Li-Tsang CW. The hand function of children with and without neurological motor disorders. The British Journal of Development Disabilities. 2003; 49 (97):99-110.

[6] Boyd R, Morris M, Graham H. Management of upper limb dysfunction in children with cerebral palsy: a systematic review. European Journal of Neurology. 2001; 8 (Suppl. 5): 150-166.

[7] Henderson A, Eliasson P. Self-Care and Hand Function. In Eliasson AC, Burtner P, editors. Improving Hand Function in Children with Cerebral Palsy: Theory, Evidence, and Intervention. London: Mac Keith Press. 2008,p: 320-338.

[8] Christianson C, Baum C. Understanding Occupation: Definitions and Concepts. In Christianson C, Baum C, editors. Occupational Therapy: Performance, Participation and WellBeing. Thorofare: Slack Inc. 1997, p: 2-25.

[9] Watson R. A population approach to transformation. In Watson R, Swartz L, editors. Transformation Through Occupation: Human Occupation in Context. London: Whurr Publishers. 2004, p: 51-66.

[10] Ramachandran VS, Rogers-Ramachandran D, Cobb S. Touching the phantom limb. Nature. 1995;377(6549):489.

[11] Yavuzer G, Selles R, Sezer N, Sutbeyaz S, Bussmann JB , Koseoglu F, Atay MB, Stam HJ. Mirror therapy improves function in subacute stroke: a randomized controlled trial. Arch Phys Med Rehabil. 2008;89:393-398.

[12] Bohannan RW, Smith MB. Interrater reliability of a modified Ashworth scale of muscle spasticity. Phys Ther. 1987; 67: 206-207.

[13] Kawamura A, Campbell K, Lam-Damji S, andFehlings D. A randomized controlled trial comparing botulinum toxin A dosage in the upper extremity of children with spasticity. Dev Med Child Neurol. 2007;49: 331-7.

[14] Reid D, Campbell K. The use of virtual reality with children with cerebral palsy: a pilot randomized trial. Ther Recreation J. 2006; 40: 255-68.

[15] Fehlings D, Rang M, Glazier J, Steele C. An evaluation of botulinum-A toxin injections to improve upper extremity function in children with hemiplegic cerebral palsy. J Pediatr. 2000;137: 331-7. 
[16] Knox V. The use of Lycra garments in children with cerebral palsy: a report of a descriptive clinical trial. Br J OccupTher. $2003 ; 66: 71-7$.

[17] Thorley M, Lannin NA, Cusick A, Novak I, Boyd R. The reliability of the Quality of Upper Extremity Skills Test for children with cerebral palsy aged 2-12 years. Phys Occup Ther Pediatr. 2012;32: 4-21.

[18] Christian H. Precision and accuracy of an electrogoniometer. J Manipulative Physio ther. 1999;22:10-14.

[19] Kuo MH, Leong CP, Cheng YF, Chang HW. Static wrist position associated with least median nerve compression: sonographic evaluation. American journal of physical medicine \& rehabilitation. 2001;80(4):256-60.

[20] Voight ML, Hardin JA, Blackburn TA, Tippett S, Canner GC. The effects of muscle fatigue on and the relationship of arm dominance to shoulder proprioception. Journal of Orthopaedic\& Sports Physical Therapy. 1996;23(6):348-52.

[21] Garry MI, Loftus A, Summers JJ. Mirror, mirror on the wall: viewing a mirror reflection of unilateral hand movements facilitates ipsilateral M1 excitability. Exp Brain Res. 2005; 163(1):118-122.

[22] Fukumura K, Sugawara K, Tanabe S, Ushiba J, and Tomita Y. Influence of mirror therapy on the human motor cortex. Int J Neurosci. 2007;117(7):1039-1048.

[23] Rizzolatti G, Fadiga L, Gallese V, Fogassi L. Premotor cortex and the recognition of motor actions. Brain Res Cogn Brain Res. 1996;3(2):131-141.

[24] Buccino G, Binkofski F, Fink GR, et al. Action observation activates premotor and parietal areas in a somatotopic manner: an fMRI study. EurJNeurosci. 2001;13(2):400-404.

[25] Dohle C, Kleiser R, Seitz RJ, Freund HJ. Body scheme gates visual processing. J Neurophysiol. 2004;91(5):2376-2379.

[26] Dohle C, Püllen J, Nakaten A, Küst J, Rietz C, Karbe H. Mirror therapy promotes recovery from severe hemiparesis: a randomized controlled trial. Neurorehabilitation and neural repair. 2009;23(3):209-17.

[27] Cavanna AE, and Trimble MR. The precuneus: a review of its functional anatomy and behavioral correlates. Brain. 2006; 129:564-583.
[28] Shmuelof L, andZohary E. A mirror representation of others' actions in the human anterior parietal cortex. J Neurosc. 2006; 26(38):9736-9742.

[29] Sütbeyaz S, Yavuzer G, Sezer N, andKoseoglu BF. Mirror therapy enhances lower-extremity motor recovery and motor functioning after stroke: A randomized controlled trial. Arch Phys Med Rehabil. 2007;88:555-9.

[30] Yavuzer G, Selles R, Sezer N, Sütbeyaz S, Bussmann JB, Köseoğlu F, et al. Mirror therapy improves hand function in subacute stroke: A randomized controlled trial. Arch Phys Med Rehabil. 2008; 89:393-8.

[31] Carson, R. G.: Neural pathways mediating bilateral interactions between the upper limbs. Brain Res Rev. 2005; 49: 641-662.

[32] Rossi S, Tecchio F, Pasqualetti P, et al. Somatosensory processing during movement observation in humans. Clin Neurophysiol. 2002;113(1):16-24.

[33] Serino A, Farne A, Rinaldesi ML, Haggard P, Làdavas E. Can vision of the body ameliorate impaired somatosensory function?. Neuropsychologia. 2007;45(5):1101-7.

[34] Sathian K, Greenspan AI, Wolf SL. Doing it with mirrors: a case study of a novel approach to neurorehabilitation. Neurorehabilitation and neural repair. 2000;14(1):73-6.

[35] Ramachandran VS, Altschuler EL, Stone L, Al-Aboudi M, Schwartz E, Siva N. Can mirror alleviate visual hemineglect? Medical hypotheses. 1999;52(4):303-5.

[36] Decety J. The neurophysiological basis of motor imagery. Behavioural brain research. 1996 May 31;77(1):45-52.

[37] Gerardin E, Sirigu A, Lehéricy S. Partially overlapping neural networks for real and imagined hand movements. Cereb Cortex. 2000;10: 1093-1104.

[38] Dunsky A, Dickstein R, Marcovitz E, et al. Home-based motor imagery training for gait rehabilitation of people with chronic poststroke hemiparesis. Arch Phys Med Rehabil, 2008, 89: 1580-1588. [PubMed]

[39] Lee H, Kim H, Ahn M, You Y. Effects of proprioception training with exercise imagery on balance ability of stroke patients. Journal of physical therapy science. 2015;27(1):1-4. 